\title{
NEW MARKETS FORECAST AND DYNAMIC PRODUCTION REDESIGN THROUGH STOCHASTIC SIMULATION
}

\author{
Bendato, I. ; Cassettari, L.; Mosca, M.; Mosca, R. \& Rolando, F. \\ Genoa University, DIME Department, Savona Campus via Magliotto 2(SV), Italy \\ E-Mail: bendato@dime.unige.it ( ${ }^{*}$ Corresponding author); cassettari@dime.unige.it; \\ marcotulliomosca@gmail.com; mosca@dime.unige.it; rolando@dime.unige.it
}

\begin{abstract}
In this paper the authors analyse a double problem: the sales forecast in new foreign markets in the next five years by an Italian SME and the consequent dynamic production system redesign having the goal to maximize the Gross Margin.

Due to the high uncertainty of the variables involved, the authors approached the study in stochastic regime. The methodology is based on Monte Carlo and Discrete Event Simulation, on new Pure Experimental Error control techniques and on Response Surface Methodology Designs as the Two Level Factorial Design and the Central Composite Design.

(Received in November 2014, accepted in March 2015. This paper was with the authors 1 month for 1 revision.)
\end{abstract}

Key Words: Sales Forecast, Production Redesign, Discrete Event Simulation, Monte Carlo Simulation, Response Surface Methodology

\section{INTRODUCTION}

The sales forecasting in a consolidated market is a difficult activity that can lead to significant discrepancies compared with actual values even if traditional forecasting models are used. Considering the sales forecasting in new foreign markets where the product is not yet sold, the problem becomes even more complex and there is no available helping literature. The authors consider the problem of supporting the growth of an Italian manufacturing SME. To face this problem, the paper presents an approach based on stochastic evaluations about the sales in the different countries, which can be, then, converted into annual production thanks to the application of the Monte Carlo techniques combined with original pure experimental error management methodologies [1-3]. Starting from this first step and using the Discrete Event Simulation (DES) and the Response Surface Methodology (RSM) techniques [4-6], it is then possible to obtain a dynamic production system redesign. The proposed methodology is applied to a single case but it is easily generalized and applied to other similar situations. The paper is organized as follows. In section 2 a full literature review is provided, highlighting the originality of the proposed approach. Section 3 shows the case study. Section 4 shows the development of a sales forecast in a stochastic regime and in section 5 a dynamic redesign of the production system is proposed. Finally, section 6 provides conclusive considerations.

\section{LITERATURE REVIEW}

The forecasting is a problem that arises in many economic and managerial contexts, and hundreds of forecasting procedures have been developed over the years for many different purposes, both in business enterprises and elsewhere. The importance of sales forecasting for a firm has often been stressed and is best expressed by what happens when it is absent: [sic] "without a sales forecast, in the short term, operations can respond only retroactively, leading to lost orders, inadequate service and poorly utilized production resources. In the longer term, financial and market decision making misallocate resources so that the organization's 
continuing existence may be brought into question"'[7]. Given that forecasts are used for a number of purposes in the firm, including production planning and personnel planning, the factors that contribute to sound forecasting practice have long been a concern in the literature $[8,9]$.

Previous forecasting studies relied on qualitative methods can be quite useful for other forecasting problems but seem inappropriate for industrial business development forecasting $[10,11]$. Recently, both theoretical and empirical results have suggested that combining forecasting methods can be an effective way to achieve better predictive performance over individual models $[12,13]$. Contributions from many researchers have improved the quality of the predictions and provided combined forecasting models for decision makers [14-18]. As a result, there have been profound changes in the forecasting field. The integration of linear and nonlinear models offers solutions that can be applied in real-world situations such as forecasting macroeconomic time series [19], tourist demand [20], and exchange rates [21]. A large number of empirical studies have focused on forecasting in general or sales forecasting, while the role of forecasting for the penetration into completely new markets has received only scant attention to date. The literature about domestic sales forecasting is deep and wide and sometimes it also concerns the case of the introduction of new products [22, 23]. However, to consider new products doesn't mean to consider new markets: this is the main topic the authors want to discuss in this work. There is a part of the forecasting literature that seems to go to this direction taking into account the forecasting role in export planning [24]. However, it differs from the research discussed in this paper because of the approaches used. In fact there is a big difference between export and introduction in new markets with the whole organizational structure. The only works about the introduction in new markets use a quite conventional, traditional and deterministic approach to the problem; for example [25] combines linear and nonlinear forecasting models. The purpose of this work is to show how to approach sales forecasting in new markets using alternative methods, such as the Monte Carlo simulation, which works in a stochastic regime.

\section{THE CASE STUDY}

\subsection{Company profile and market}

The company is an Italian SME employing 52 people that has been operating for over 40 years. The market opportunities have changed and they evolve ceaselessly, the purchasing logics are more rigid than in the past and alternatives are sought. Therefore it is important to develop sales in new markets.

The Company's brand and product must be shown to the dealers, appreciated and their advantage demonstrated. The barrier to change must be overcome, approved, proposed as an alternative to the clients, tried by the clients and replaced by them (a progressive growth until stability is achieved). Each year therefore it is necessary to consolidate the sales of the previous one and to lay the basis for the following one.

This requires time, but it leads to a sound and gradual growth, each year even more credible for the new approached markets, because it has the successful experience achieved in the countries already colonized.

\subsection{The strategic plan}

The proposed strategy consists in adding Regions until the EMEA (Europe, Middle East and Africa) \& LATAM (Latin Americas) areas are covered, through a progressive, diversified and global growth plan (2015: EMEA + EU + BRAZIL; 2016: EMEA + LATAM; 2017: USA + 
CANADA East Coast; 2018: USA + CANADA West Coast). Sales projections for the future years are estimated in order to have the manufacturing capacity of each line of the factory. Such projections are obtained from an accurate market research that allows the creation of three scenarios: the most likely hypothesis, the lower and the upper bound.

\subsection{Projection of sales in a deterministic regime}

Referring to the case study, in this section the sales forecasting based on a deterministic approach are shown. Table I shows the sales forecast obtained in 2014. The same is done for the following years considering the newly available information.

Table I: Sales expected in the years, joining in 2015.

\begin{tabular}{|c|c|c|c|c|c|c|c|c|c|c|c|c|c|c|c|c|c|c|}
\hline \multirow{3}{*}{$\begin{array}{l}\text { Forecast } 2014 \\
\text { growth factor based on previous year } \\
\text { CENTRAL EU, Reinhard }\end{array}$} & \multicolumn{3}{|c|}{2015} & \multicolumn{3}{|c|}{2016} & \multicolumn{3}{|c|}{2017} & \multicolumn{3}{|c|}{2018} & \multicolumn{3}{|c|}{2019} & \multicolumn{3}{|c|}{2020} \\
\hline & \multicolumn{3}{|c|}{ na } & \multicolumn{3}{|c|}{1,7} & \multicolumn{3}{|c|}{2} & \multicolumn{3}{|c|}{1,3} & \multicolumn{3}{|c|}{1,3} & \multicolumn{3}{|c|}{1,3} \\
\hline & Lower & Mostlike & Upper & Lower & Mostlike & Upper & Lower & Mostlike & Upper & Lower & Mostlike & Upper & Lower & Mostlike & Upper & Lower & Mostlike & Upper \\
\hline 1 GERMANY & 300 & 1.500 & 2,250 & 510 & 2.550 & 3.825 & 1.020 & 5.100 & 7.650 & 1.326 & 6.630 & 9.945 & 1.724 & 8.619 & 12.929 & 2.241 & 11.205 & 16.807 \\
\hline 2 SWITZERLAND & so & 250 & 375 & 85 & 425 & 638 & 170 & 850 & 1.275 & 221 & 1.105 & 1.658 & 287 & 1.437 & 2.155 & 373 & 1.867 & 2.801 \\
\hline 3 AUSTRLA & 50 & 250 & 375 & 85 & 425 & 638 & 170 & 850 & 1.275 & 221 & 1.105 & 1.658 & 287 & 1.437 & 2.155 & 373 & 1.867 & 2.801 \\
\hline 4 POLAND & 100 & 500 & 750 & 170 & 850 & 1.275 & 340 & 1.700 & 2.550 & 442 & 2.210 & 3.315 & 575 & 2.873 & 4.310 & 747 & 3.735 & 5.602 \\
\hline S(KAZACHSTAN) & 70 & 350 & 525 & 119 & 595 & 893 & 238 & 1.190 & 1.785 & 309 & 1.547 & 2.321 & 402 & 2.011 & 3.017 & 523 & 2.614 & 3.922 \\
\hline LATIN COUNTRIES, Maria & 570 & 2.850 & 4.275 & 969 & 4.845 & 7.268 & 1.938 & 9.690 & 14.535 & 2.519 & 12.597 & 18.896 & 3.275 & 16.376 & 24.564 & 4.258 & 21.289 & 31.933 \\
\hline 6 PORTUGAL & so & 250 & 500 & 85 & 425 & 850 & 170 & 850 & 1.700 & 221 & 1.105 & 2.210 & 287 & 1.437 & 2.873 & 373 & 1.867 & 3.735 \\
\hline 7 SPAIN & 100 & 500 & 1.000 & 170 & 850 & 1.700 & 340 & 1.700 & 3.400 & 442 & 2.210 & 4.420 & 575 & 2.873 & 5.746 & 747 & 3.735 & 7.470 \\
\hline 8 BRAZIL & 350 & 1.750 & 3.500 & 595 & 2.975 & 5.950 & 1.190 & 5.950 & 11.900 & 1.547 & 7.735 & 15.470 & 2.011 & 10.056 & 20.111 & 2.614 & 13.072 & 26.144 \\
\hline UK \& EIRE, Simon & 500 & 2.500 & 5.000 & 850 & 4.250 & 8.500 & 1.700 & 8.500 & 17.000 & 2.210 & 11.050 & 22.100 & 2.873 & 14.365 & 28.730 & 3.735 & 18.675 & 37.349 \\
\hline 9 ENGLAND & 100 & 500 & 1.250 & 170 & 850 & 2.125 & 340 & 1.700 & 4.250 & 442 & 2.210 & 5.525 & 575 & 2.873 & 7.183 & 747 & 3.735 & 9.337 \\
\hline 10 SCOTHLANO & so & 300 & 750 & 85 & 510 & 1.275 & 170 & 1.020 & 2.550 & 221 & 1.326 & 3.315 & 287 & 1.724 & 4.310 & 373 & 2.241 & 5.602 \\
\hline $\mathbf{1 1}$ WALES & so & 200 & 500 & 85 & 340 & 850 & 170 & 680 & 1.700 & 221 & 884 & 2.210 & 287 & 1.149 & 2.873 & 373 & 1.494 & 3.735 \\
\hline 12 NORTH IRELAND & 50 & 100 & 250 & 85 & 170 & 425 & 170 & 340 & 850 & 221 & 442 & 1.105 & 287 & 575 & 1.437 & 373 & 747 & 1.867 \\
\hline 13 SOUTHIRELAND & 50 & 100 & 250 & 85 & 170 & 425 & 170 & 340 & 850 & 221 & 442 & 1.105 & 287 & 575 & 1.437 & 373 & 747 & 1.867 \\
\hline EXYUGOSLAVIA, SOSSI & 300 & 1.200 & 3.000 & 510 & 2.040 & 5.100 & 1.020 & 4.080 & 10.200 & 1.326 & 5.304 & 13.260 & 1.724 & 6.895 & 17.238 & 2.241 & 8.964 & 22.409 \\
\hline 14 SLOVENIA & 100 & 500 & 1.000 & 170 & 850 & 1.700 & 340 & 1.700 & 3.400 & 442 & 2.210 & 4.420 & 575 & 2.873 & 5.746 & 747 & 3.735 & 7.470 \\
\hline I5 CROAZIA & 100 & 500 & 1.000 & 170 & 850 & 1.700 & 340 & 1.700 & 3.400 & 442 & 2.210 & 4.420 & 575 & 2.873 & 5.746 & 747 & 3.735 & 7.470 \\
\hline 1680 SNIA & 50 & 250 & 500 & 85 & 425 & 850 & 170 & 850 & 1.700 & 221 & 1.105 & 2.210 & 287 & 1.437 & 2.873 & 373 & 1.867 & 3.735 \\
\hline 17 HERZEGOVINA & 50 & 250 & 500 & 85 & 425 & 850 & 170 & 850 & 1.700 & 221 & 1.105 & 2.210 & 287 & 1.437 & 2.873 & 373 & 1.867 & 3.735 \\
\hline 18 SERBIA & so & 250 & 500 & 85 & 425 & 850 & 170 & 850 & 1.700 & 221 & 1.105 & 2.210 & 287 & 1.437 & 2.873 & 373 & 1.867 & 3.735 \\
\hline 19 MONTENEGRO & 10 & so & 100 & 17 & 85 & 170 & 34 & 170 & 340 & 44 & 221 & 442 & 57 & 287 & 575 & 75 & 373 & 747 \\
\hline 20 MACEDONIA & 10 & 50 & 100 & 17 & 85 & 170 & 34 & 170 & 340 & 44 & 221 & 442 & 57 & 287 & 575 & 75 & 373 & 747 \\
\hline \multirow[t]{3}{*}{21 kosovo } & 10 & 50 & 100 & 17 & 85 & 170 & 34 & 170 & 340 & 44 & 221 & 442 & 57 & 287 & 575 & 75 & 373 & 747 \\
\hline & 380 & 1.900 & 3.800 & 646 & 3.230 & 6.460 & 1.292 & 6.460 & 12.920 & 1.680 & 8.398 & 16.796 & 2.183 & 10.917 & 21.835 & 2.839 & 14.193 & 28.385 \\
\hline & 1.750 & 8.450 & 16.075 & 2.975 & 14.365 & 27.328 & 5.950 & 28.730 & 54.655 & 7.735 & 37.349 & 71.052 & 10.056 & 48.554 & 92.367 & 13.072 & 63.120 & 120.077 \\
\hline
\end{tabular}

\subsection{Limits of the deterministic regime}

As it has already been evidenced in the previous sections, the study of the operational reality in deterministic regime leads to construction of models whose results are different from those generated by the real system. Even this application case could not be different, since the turnover of the different years originate from the combination of a minimum of 21 up to a maximum of over 60 probability density distributions. The deterministic approach, even if carefully weighted and based on scenarios, does not allow the pure error assessment which could give the authors the necessary confidence in recommending the Company the investments needed to proceed. It is therefore absolutely necessary to use models that can evolve in a stochastic regime to carry out an analysis that can produce reliable results. The literature has recently seen, with specific reference to problems of forecasting, works based on Markovian chains. However, the authors prefer to work on the operationally more reliable ground of the Monte Carlo simulation [26]. 


\section{DEVELOPMENT OF A SALES FORECAST IN A STOCHASTIC REGIME}

In the case under examination, the authors want to develop the sales forecasting of the six future years in a stochastic regime, starting from the assumed probabilistic scenarios, in order to get forecasts more faithful to the evolution of the real business system. Such forecasts will be known as mean value, confidence interval and tolerance interval on the punctual response of the simulator. These are necessary elements for a correct interpretation of the obtained result by the Management.

\subsection{Procedural steps}

To this purpose, it is evaluated the variability of the total turnover in the geographical areas (called Regions) taken into consideration between 2015 and 2020. The Regions are made up by one or more countries. The analysis implies a turnover forecast, year by year, on the basis of the data previously estimated by the buyers, for each individual country, in terms of sales volumes. These latter ones are expressed in the shape of triangular probability distributions represented by the "Lower", "Most like" and "Upper" values. As it can be easily noticed from Table I, each country is defined by a distribution of the sales volume that increases by a constant growth factor over the previous year. Each Region is defined by a distribution of the sales volumes represented by the sum of the distributions of the individual countries. Furthermore, in relation to the value assumed by the distribution, a variation is considered in the sale price. The distribution of each individual sales volume produces, therefore, an expected turnover still distributed according to a triangular probability density function. Having decided to use the Monte Carlo simulation as the tool to treat the stochasticity, the critical point of the study refers to the determination of the simulation runs length using the evolution curve of the pure experimental error of the mean and of the standard deviation [27]. Taking into consideration that the experimental error, in the Monte Carlo simulation, decreases with the increase of the replicated runs number until reaching zero, the task of the experimenter becomes to search for the best ratio, in a stabilized curve, between the run time length and minimization of the intervals width. Following these considerations, the variability of the expected turnover is studied, year by year, to determine the most appropriate number of runs to maximize the relation between the experimentation computational effort and the accuracy of the result.

\subsection{MSPE evaluation}

It is precisely the population variance that is destined to grow over the years. This as a consequence of the inevitable growth of the uncertainty margin linked to events that are continuously translated to the future. Just for this reason, considering the Company's turnover, the authors have thought, before proceeding to the setup of the entire experimental campaign, to carry out a preliminary trial test to evaluate the possible stabilization of the two Mean Square Pure Error (MSPE) curves. From the analysis of the graphs of the MSPE of the mean and the MSPE of the standard deviation (Figs. 1 and 2), it is immediately evident that in some cases (the first years) 20.000 runs are sufficient for the curves stabilization while, for the following years, 20.000 runs are insufficient to carry out a correct analysis on the model. This is due to the fact that both MSPE curves show clear signs of an unachieved stabilization. As a consequence, the horizon of the replicated runs has been progressively increased, first to 30.000 and later to 50.000, with a noticeable increase of the computational effort which grows more rapidly than linearly. Further possible increases in the number of runs, absolutely 
necessary to reduce the MSPE of the standard deviation, are not really necessary since they are unable to produce significant reductions in the width of the tolerance intervals (Fig. 3).

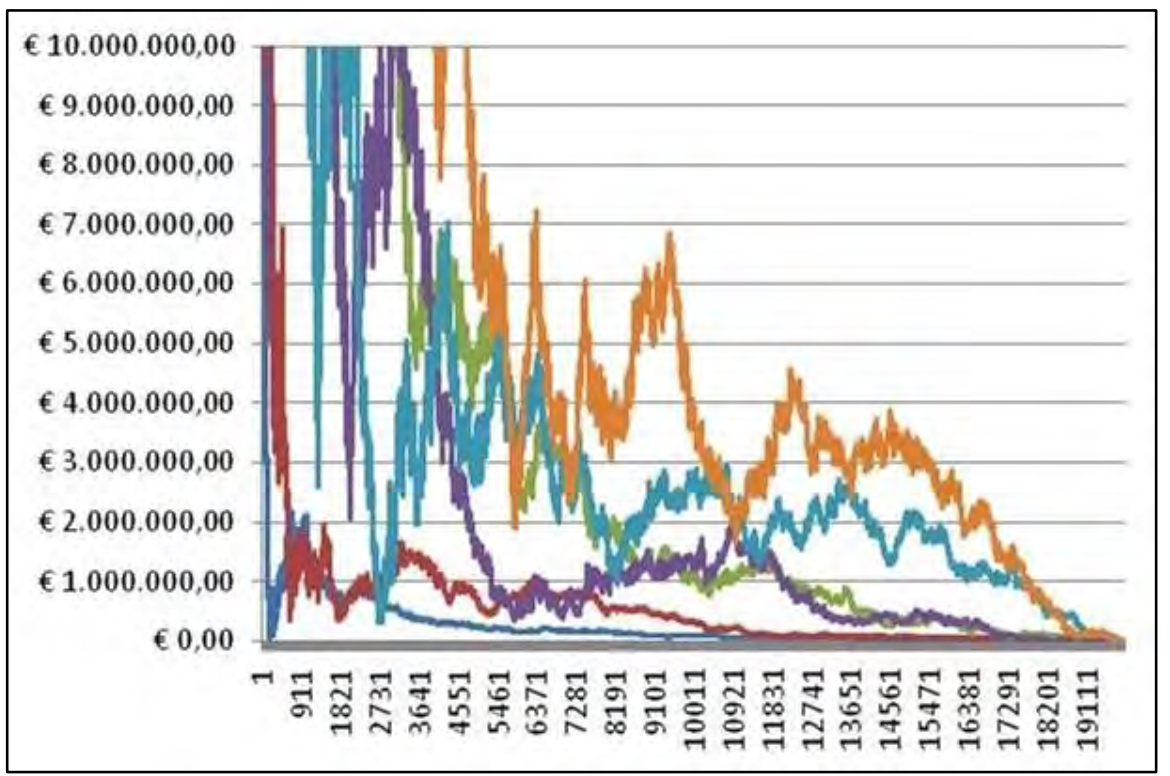

Figure 1: MSPE of the mean.

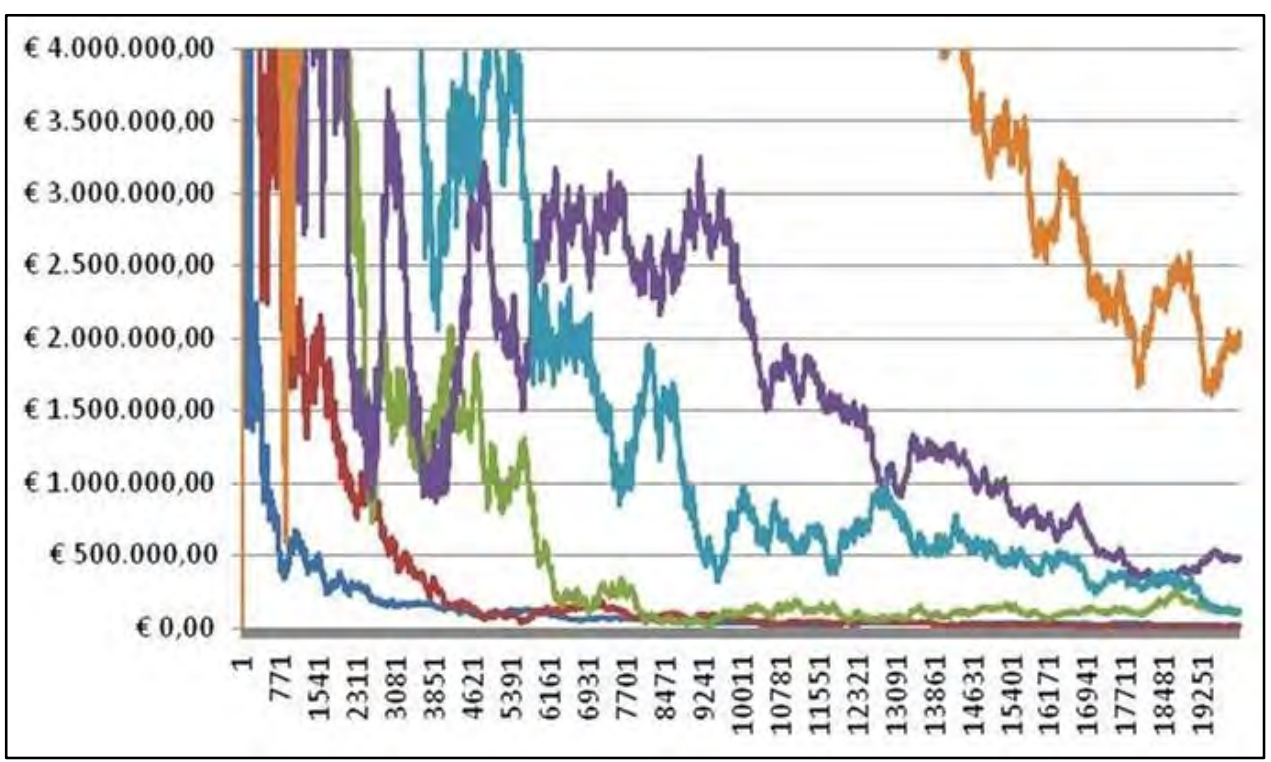

Figure 2: MSPE of the standard deviation.

It is useful to remark that the tolerance interval is a necessary element to evaluate the oscillation width of the response, distributed, according to theory, as a Normal Distribution probability density function under the chosen number of replications.

\subsection{Lessons learned}

Some interesting considerations, both under a managerial and under a methodological point of view, are:

1) the MSPE methodology, by allowing estimating the variance of the experimental error, permits evaluating the width of the tolerance interval (that is of the value limits of the turnover). Within it is possible to be confident, with a probability of over $99 \%$ that the true value of the turnover will fall if, obviously, the starting hypothesis is correct. From the 
construction, instead, of the $90 \%$ confidence interval it is possible to obtain the interval inside which being confident that, for 90 times out of 100, the mean value of the turnover will fall. Compared to a precise mean value of a deterministic regime, the obtained result (proceeding from the analysis of 66 frequency distributions of the expected sales) represents a fundamental step for the determination of a forecast. Consequently, it also allows studying a correct dimensioning of the production system. Starting, in fact, from the data obtained for 2020 , it is possible for the management, under the viewpoint of a five-year planning, to determine, again through a DES simulation, the dimensioning, both physical of the productive site (no. of machines, no. of operators, etc.) and economical-financial of the entire Company.

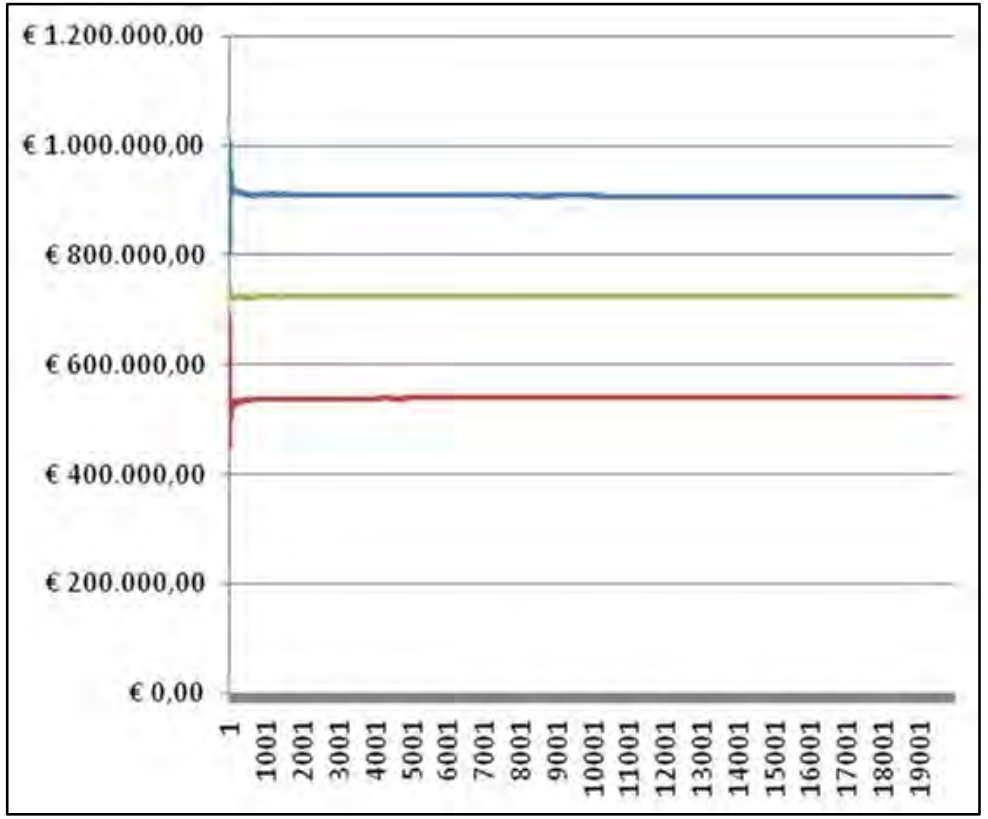

Figure 3: Tolerance intervals of revenues as function of the runs number.

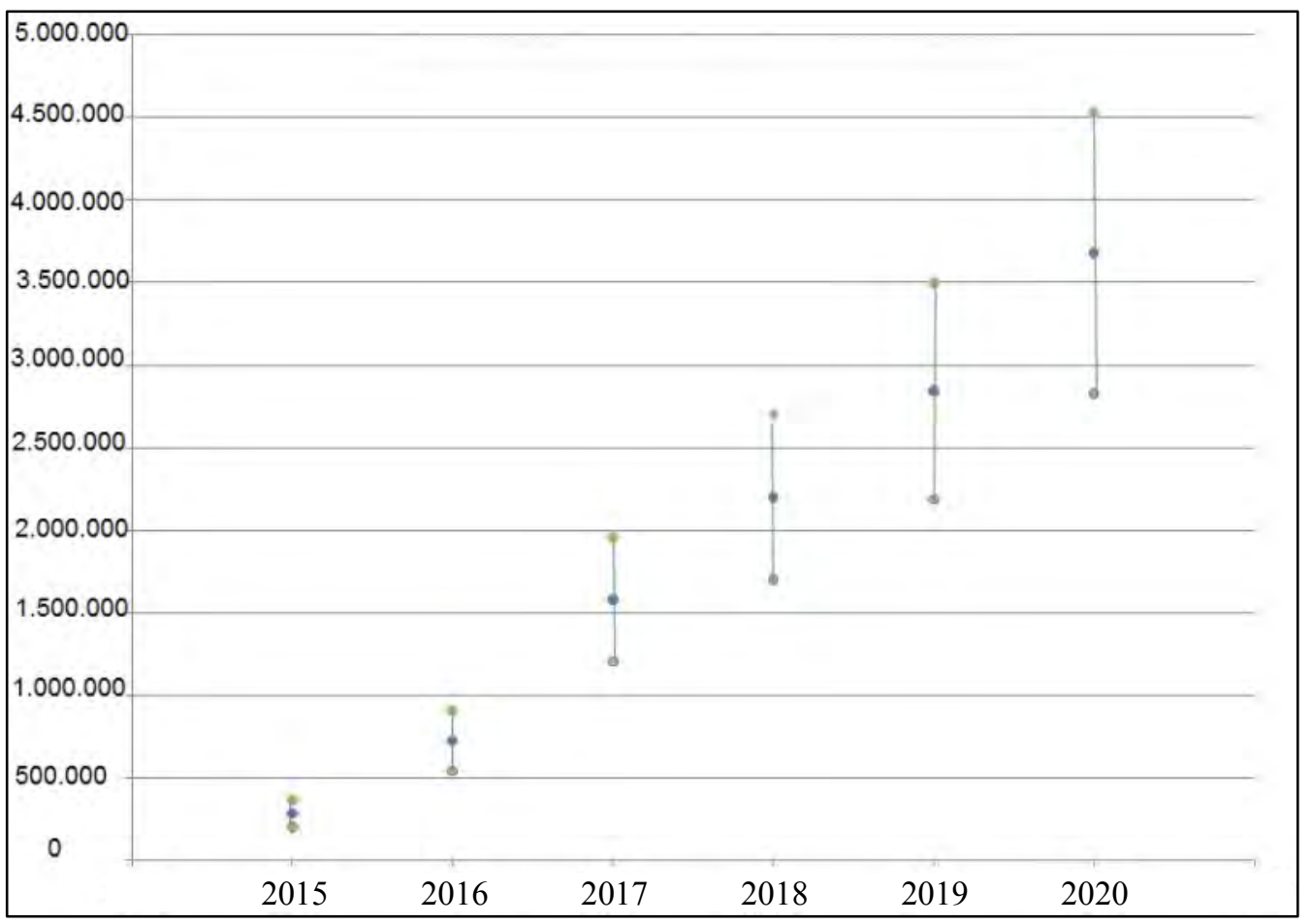

Figure 4: Mean value and tolerance interval of revenues per year. 
Table II: Summary of parameters in function of replicated runs.

\begin{tabular}{|l|c|r|r|r|r|r|r|r|r|}
\cline { 2 - 10 } \multicolumn{1}{c|}{} & $\begin{array}{c}\text { Run } \\
\text { length }\end{array}$ & $\begin{array}{c}\text { Mean } \\
\text { turnovers }\end{array}$ & $\begin{array}{c}\text { Interval } \\
\text { width }\end{array}$ & $\begin{array}{c}\text { Higher } \\
\text { limit }\end{array}$ & $\begin{array}{c}\text { Lower } \\
\text { limit }\end{array}$ & $\begin{array}{c}\text { MSPE } \\
\text { mean }\end{array}$ & $\begin{array}{c}\text { Variance } \\
\text { turnover }\end{array}$ & $\begin{array}{c}\text { Standard } \\
\text { deviation }\end{array}$ & $\begin{array}{c}M S P E \\
\text { stdev }\end{array}$ \\
\hline 2015 & 20.000 & 284.955 & 82.527 & 367.482 & 202.428 & 156 & 756.030 .016 & 27.496 & 13.220 \\
\hline 2016 & 20.000 & 723.969 & 182.167 & 906.136 & 541.802 & 109 & 3.685 .946 .944 & 60.712 & 122 \\
\hline 2017 & 30.000 & 1.582 .343 & 377.950 & 1.960 .293 & 1.204 .393 & 145 & 15.868 .692 .841 & 125.971 & 115.969 \\
\hline 2018 & 30.000 & 2.201 .365 & 502.152 & 2.703 .517 & 1.699 .213 & 47 & 28.014 .725 .376 & 167.376 & 231.336 \\
\hline 2019 & 50.000 & 2.845 .047 & 635.214 & 3.498 .261 & 2.191 .833 & 6 & 47.713 .412 .356 & 217.735 & 139.801 \\
\hline 2020 & 50.000 & 3.680 .434 & 851.275 & 4.531 .709 & 2.829 .159 & 0 & 80.517 .467 .536 & 283.756 & 1.160 .788 \\
\hline
\end{tabular}

As it can be seen from Table II, the turnover mean value grows, as expected, over time according to the precise values. The tolerance intervals, in conformity with the uncertainty level that grows over time, result growing as shown in Fig. 4.

2) From the comparative analysis of the different years (Table II) it is possible, furthermore, to observe how, as the dimension of the 5 samples used to calculate the MSPE, grows from 20.000 to 50.000 runs. According to theory, the mean MSPE tends to 0 and the mean value of the model responses, obtained from the distribution of the mean of the means, tends to converge to the mean value of the population distribution. The growing width of the variance $(V A R)$ is, obviously, linked to the growth of the uncertainty imposed by the forecast data in the future years. It may be observed how, even if the MSPE standard deviation (MSPEstdev) in 2020 has a value around 106 , actually its capacity to influence the tolerance interval is nearly negligible. This is because this value, translated in terms of standard deviation of the distribution of the mean of the variances, is just around one thousand Euros. To realize this, it is sufficient to observe the half width tolerance interval structure (1):

$$
3 \sqrt{\mathrm{MSPE}_{\mathrm{MED}}}+3 \sqrt{\overline{\mathrm{VAR}}+\mathrm{MSPE}_{\mathrm{STDEV}}}
$$

The half width tolerance interval in 2020 is:

$$
3 \sqrt{0,05}+3 \sqrt{80517467536+1160788}=851275
$$

Vice versa, the explanation of the width of the confidence intervals must be ascribed totally to the VAR. The confidence intervals can be obtained following (3):

$$
\text { mean turnover } \pm t_{\dot{\alpha} / 2}\left(\frac{\text { stdev }}{\sqrt{n}}\right)
$$

The confidence interval in 2020 is:

$$
3680434 \pm 2,132\left(\frac{283756}{\sqrt{5}}\right)=270550
$$

3) As may be easily inferred, the value of MSPE of the standard deviation may be reduced by increasing the number of replicated runs. Vice versa, a computational effort would be necessary and it is not justified by the significance of the result that can be obtained.

\section{DYNAMIC REDESIGN OF THE PRODUCTION SYSTEM}

In order to satisfy the increasing sale volumes defined in the strategic plan, another study is made to determine the optimum size of the production line for each year.

The production model is made of two parallel production lines, each one with different operations in sequence, that then join into one single line until the end of the process as shown in Fig. 5. The Discrete Event Simulation model is realized using the tool Flexsim, developed by Flexsim Software Products. Starting from Work Breakdown Structure (WBS), the whole production system is recreated and simultaneously the time statistical distributions of the different processing phases are identified. At this point, thanks to the use of a stochastic 
discrete event simulator [28], combined with Design of Experiments (DoE) and RSM techniques, it is possible to obtain statistically reliable results of the supposed production model $[29,30]$ and to verify the different layout and organizational options.

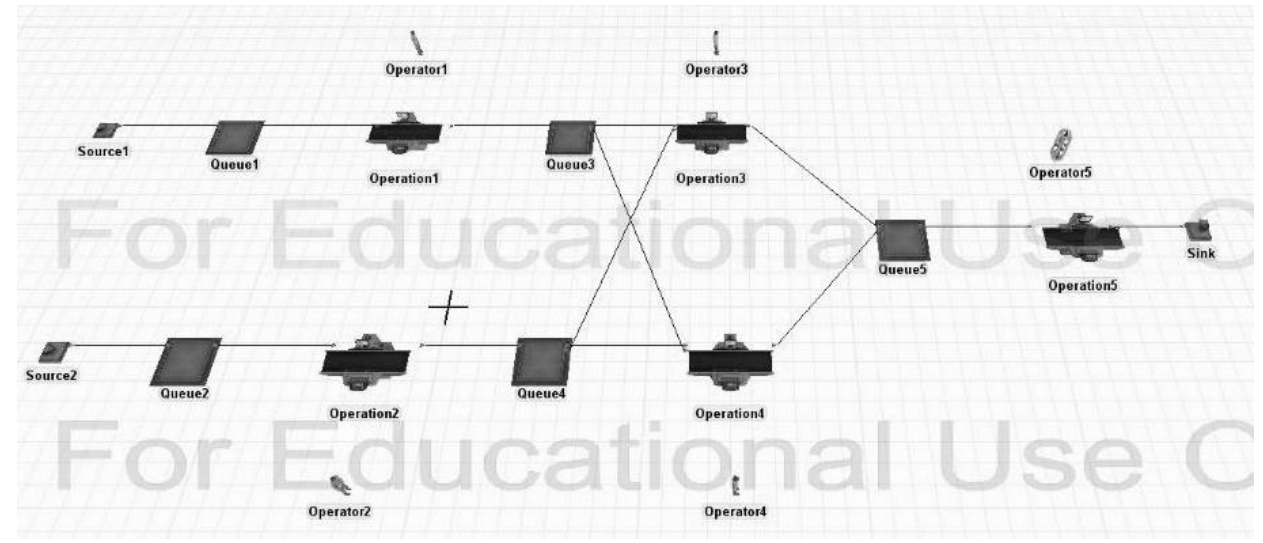

Figure 5: Production system.

\subsection{MSPE calculation}

The first important phase in the simulative approach is the MSPE calculation, necessary to determine the optimal length of the simulation run. The methodology is similar to the one used in the first part of the paper, for the run-evolving systems.

However, in the first part the goal is to determine the sample size which allows extending the considerations on mean and standard deviation to the whole population, while, in a timeevolving system, the study regards the curve stabilization on the error which represents the stochasticity of the real system. Since the data are referred to a cumulative variable (the production), it is necessary to normalize the responses to obtain the production per shift.

These values are averaged and then the MSPE is calculated.

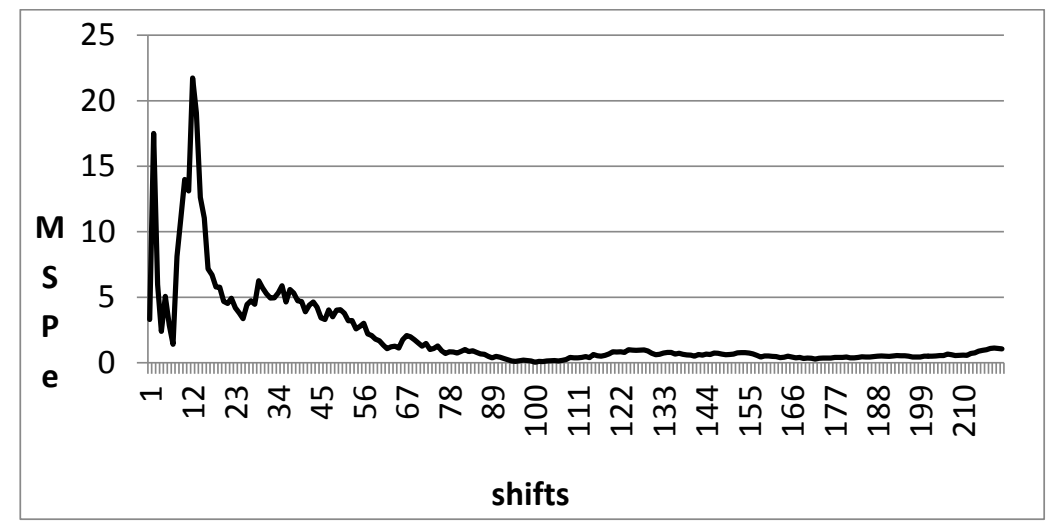

Figure 6: Production MSPE (pieces²/shift).

As shown in Fig. 6, the MSPE curve settles at shift 200 and so this is the optimal run length (about 5.760.000 s). Now the tolerance interval can be obtained using the mean production (163,52 piece/shift) and the MSPE corresponding to the chosen run length $(0,498$ $\mathrm{piece} / \mathrm{shift})$.

$$
163,52-3 \sqrt{0,498} \leq y \leq 163,52+3 \sqrt{0,498}
$$

The production is organized in team work so it is necessary to define the optimum teams number needed in the new working configuration. 


\subsection{Teams number calculation}

Thanks to the simulation results, the optimal teams number needed to meet the forecasts can be obtained by calculating the number of needed shifts. Considering a representative year forecast, the minimum and maximum shift number can be calculated dividing the total production by, respectively, the maximum (161,4 pcs/shift) and minimum (165,6 pcs/shift) shift output (Table III). Then, considering 1760 hours per year for each team, the minimum and maximum teams number is calculated (Table III). In the following part of the paper the authors always consider the maximum teams number to guarantee the needed production level even in negative situations.

Table III: Teams number calculation.

\begin{tabular}{|c|c|c|c|c|c|c|c|}
\hline Year & $\begin{array}{c}\text { Total } \\
\text { production }\end{array}$ & $\begin{array}{c}\text { Minimum } \\
\text { shift number }\end{array}$ & $\begin{array}{c}\text { Maximum } \\
\text { shift number }\end{array}$ & $\begin{array}{c}\text { Minimum } \\
\text { number of hours }\end{array}$ & $\begin{array}{c}\text { Maximum } \\
\text { number of hours }\end{array}$ & $\begin{array}{c}\text { Minimum } \\
\text { teams } \\
\text { number }\end{array}$ & $\begin{array}{c}\text { Maximum } \\
\text { teams } \\
\text { number }\end{array}$ \\
\hline 2016 & 36000,00 & 217,39 & 223,05 & 1739,13 & 1784,39 & 1 & 2 \\
\hline 2017 & 42000,00 & 253,62 & 260,22 & 2028,99 & 2081,78 & 2 & 2 \\
\hline 2018 & 45600,00 & 275,36 & 282,53 & 2202,90 & 2260,22 & 2 & 2 \\
\hline 2019 & 50280,00 & 303,62 & 311,52 & 2428,99 & 2492,19 & 2 & 2 \\
\hline 2020 & 56364,00 & 340,36 & 349,22 & 2722,90 & 2793,75 & 2 & 2 \\
\hline
\end{tabular}

It can be noticed that an increase in production does not necessarily mean an increase in the teams number. A more detailed analysis on the production level may be conducted by analysing the influence of some factors on the objective function. In the case study the objective function identified is the Gross Margin while the investigated factors are the worker ability and the stock level. These factors are considered as the main factors because:

- an unskilled operator has a lower return, and therefore leads to a decrease in production and consequently in the margin. With experienced operators, the opposite effect occurs instead.

- a high stock level allows to always satisfy the request, but also causes high inventory costs. A low stock level instead allows to have lower inventory costs but it causes different costs generated by non-sale.

To approach this kind of problem it is necessary to use a DoE analysis.

\subsection{DoE and RSM analysis}

DoE is one of the mathematical and statistical methods used by the RSM [30] to optimize an objective function.

Using the DoE techniques the influence of the worker ability and of the stock level on the Gross Margin can be investigated. The used methodology is the $2^{k}$ (in particular a $2^{2}$ ) factorial design which requires the minimum number of levels studying $k$ factors. Fig. 7 represents the experimental points that a $2^{2}$ factorial design needs: 4 design points on the vertices and 3 to 5 central points.

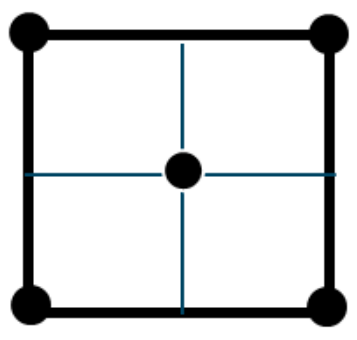

Figure 7: $2^{2}$ factorial design. 
For the first factor (worker ability), named factor A, the two considered levels are:

- high level: $115 \%$ efficiency,

- low level: $85 \%$ efficiency.

For the second factor (stock level), named factor B, the two considered levels are:

- high level: $100 \%$ total production,

- low level: $30 \%$ total production.

In order to evaluate the stock performance during the year, the monthly production variation is considered. For each month the authors consider all the possible combinations of the factor levels (also considering the average levels of $100 \%$ efficiency for the worker ability and $60 \%$ of production for the stock level). If all factors are considered at the central level, the replications become five (corresponding to the five central points) as already shown in Fig. 7.

RSM procedural steps:

- calculate the margin concerning the worker level:

$$
\frac{\text { turnover-direct costs-directized costs-indirect costs }}{\text { total production }}
$$

where directized costs stands for the part of the indirect costs which can be related directly on the production. The worker level affects the total production and the manpower costs, included in the direct costs, as the hourly cost of a low-level worker is $13 € / \mathrm{h}$, the medium level is $17 € / \mathrm{h}$ and the high-level is $20 € / \mathrm{h}$.

- calculate the average stock starting from the data normalization obtained from Flexsim,

- calculate the unit material costs:

$$
\frac{\text { direct costs-manpower costs }}{\text { total production }}
$$

- calculate the inventory cost as (average stock $\times$ unit material cost $\times i$ ) where $i=0.3$ is the storage cost,

- calculate the gross margin as (margin concerning the worker level $\times$ monthly production stock cost),

- calculate the total Gross Margin related to each scenario as the sum of the individual monthly margins.

\begin{tabular}{|c|c|c|c|c|c|}
\hline \multicolumn{6}{|c|}{$\begin{array}{lll}\text { Response } & 1 & \text { gross margin }\end{array}$} \\
\hline \multicolumn{6}{|c|}{ ANOVA for Response Surface Reduced Cubic Model } \\
\hline \multicolumn{6}{|c|}{ Analysis of variance table [Partial sum of squares - Type III] } \\
\hline & Sum of & & Mean & $\mathrm{F}$ & p-value \\
\hline Source & Squares & df & Square & Value & Prob $>F$ \\
\hline Block & $2.373 E+008$ & 1 & $2.373 E+008$ & & \\
\hline Model & 4.131E+010 & 6 & $6.885 E+009$ & 15505.66 & significant \\
\hline A-Livello op & $2.821 E+009$ & 1 & $2.821 E+009$ & 6352.07 & $<0.0001$ \\
\hline B-Livello sc & $8.718 E+009$ & 1 & $8.718 E+009$ & 19634.71 & $<0.0001$ \\
\hline$A B$ & $1.102 E+008$ & 1 & 1.102E+008 & 248.15 & $<0.0001$ \\
\hline$A^{2}$ & $3.659 E+008$ & 1 & $3.659 E+008$ & 823.97 & $<0.0001$ \\
\hline$B^{2}$ & $4.080 E+009$ & 1 & $4.080 E+009$ & 9188.37 & $<0.0001$ \\
\hline$A^{2} B$ & $3.839 E+008$ & 1 & $3.839 E+008$ & 864.47 & $<0.0001$ \\
\hline Residual & $2.220 E+006$ & 5 & $4.440 E+005$ & & \\
\hline Leck of Fit & $4.273 E+005$ & 1 & 4.273E+005 & 0.95 & 0.3842 not significant \\
\hline Pure Error & $1.793 E+006$ & 4 & $4.482 E+005$ & & \\
\hline Cor Total & 4.155E+010 & 12 & & & \\
\hline
\end{tabular}

Table IV: CCD ANOVA.

The Gross Margins are then used as input data for DoE. The ANOVA table shows that a first-order model does not fit the reality since the Lack of Fit Test is "significant". For this 
reason it is necessary to switch to a Central Composite Design (CCD) to try to fit with a second-order model $[31,32]$. This time the Lack of Fit Test is not significant so the secondorder model fits the real model. The ANOVA and the response surface resulting from the new approach are shown in Table IV and in Fig. 8.

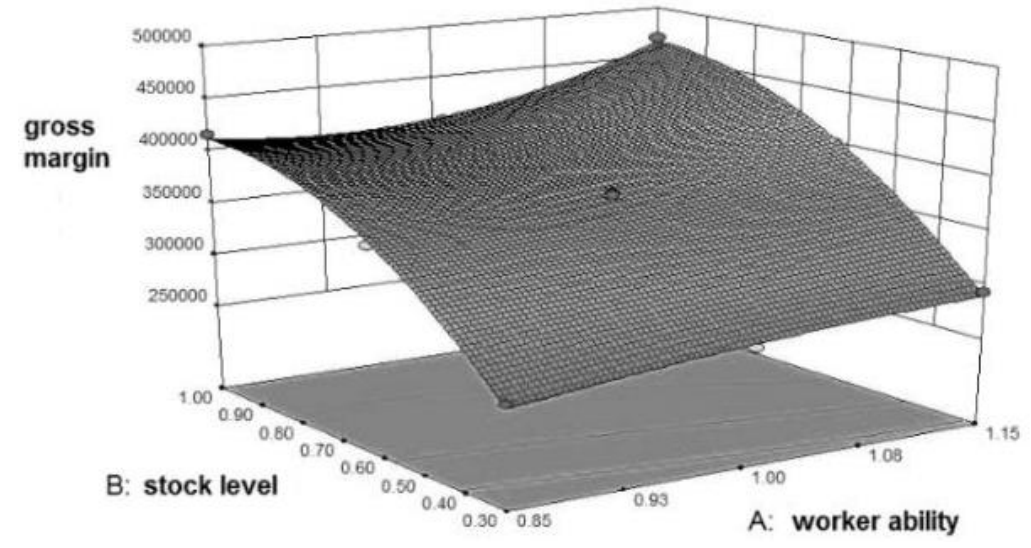

Figure 8: CCD response surface.

As shown in Table IV the significant factors are: $A ; B ; A B ; B^{2} ; A^{2} ; A^{2} B$. So the regressive model expression is [33]:

$$
\text { Gross Margin }=384400+21718 A+66024 B+5230 A B+11577 A^{2}+39465 B^{2}+6967 A^{2} B
$$

Moreover analysing the vertices of Fig. 8 it can be noticed that when both factors are at the low level, the minimum Gross Margin is obtained because the worker low level involves a lower production and the low stock level involves a large number of stops.

The situation does not improve if only the worker level is increased because, although the worker is more efficient, the low stocks do not allow an adequate supply. Instead, the stock level has the greatest impact on the system because, keeping down the worker level and increasing the stocks, the Gross Margin grows.

To find the optimum, however, it is necessary to vary the worker level, bringing it to the high level, to ensure a better efficiency. The optimal solution is then obtained setting the worker level to $115 \%$ and the stock level to $100 \%$. The gross margin is about $466.451 € /$ year (considering a typical year).

\subsection{Cost analysis}

After having defined the production for the new market and identified the production system redesign, it is necessary to look at the sustainability of the internationalization process. This can be done by evaluating the Gross Margin, being aware of the sales forecast. The Gross Margin concerning 2016 can be directly evaluated using eq. (6), since all the needed data are known. For the following years, the formula is applied after calculating the new direct costs and the directized cost, using the economy of scale (Table V).

Economies of scale are the cost advantages that enterprises obtain due to size, output, or scale of operation, with cost per unit of output generally decreasing with increasing scale as fixed costs are spread out over more units of output. Often operational efficiency is also greater with increasing scale, leading to lower variable cost as well. As far as indirect costs are concerned, they are fixed and do not change.

Direct costs include: manpower costs (calculated on the basis of the number of people in a team and of their cost, depending on their specialization level) and material costs (calculated through the economy of scale). Finally, we calculate the turnovers and then the margins, using again eq. (6). 
Table V: Economy of scale.

\begin{tabular}{|l|c|c|c|c|c|}
\hline \multicolumn{1}{|c|}{ Year } & 2016 & 2017 & 2018 & 2019 & 2020 \\
\hline Production & 36.000 & 42.000 & 45.600 & 50.280 & 56.364 \\
\hline Manpower costs & 176.821 & 176.821 & 176.821 & 176.821 & 176.821 \\
\hline Unit material costs & 12,83 & 5,77 & 5,90 & 6,03 & 6,16 \\
\hline Material costs & 461.831 & 242.461 & 269.093 & 303.161 & 347.075 \\
\hline Indirect costs & 638.652 & 419.282 & 445.915 & 479.982 & 523.896 \\
\hline
\end{tabular}

For 2016, all the data are known while for the following years the production is known and manpower costs are calculated as (number of persons $\times$ hourly cost concerning efficiency $\times$ number of hours) bearing in mind that $15 \%$ of the manpower is highly specialized.

In addition to the cost recalculation, the prices have to be defined considering some discounts. The list price is $99,7 € /$ pcs and the applied reductions are $45 \%$ in Italy and $60-70 \%$ abroad. The Gross margin increase (Table VI) confirms the internationalization project feasibility.

Table VI: Gross margins.

\begin{tabular}{|l|c|c|c|c|c|}
\hline \multicolumn{1}{|c|}{ Year } & 2016 & 2017 & 2018 & 2019 & 2020 \\
\hline Production & 36.000 & 42.000 & 45.600 & 50.280 & 56.364 \\
\hline Foreign price & & 30 & 30 & 30 & 30 \\
\hline Turnover & 1.798 .563 & 1.708 .920 & 1.816 .596 & 1.956 .575 & 2.138 .547 \\
\hline Direct costs & 638.652 & 419.282 & 445.915 & 479.982 & 523.896 \\
\hline Directized costs & 145.786 & 170.100 & 184.680 & 203.634 & 228.274 \\
\hline Indirect costs & 455.769 & 455.769 & 455.769 & 455.769 & 455.769 \\
\hline Gross margin & 15,51 & 15,80 & 16,01 & 16,25 & 16,51 \\
\hline
\end{tabular}

\section{CONCLUSIONS}

The problem considered by the authors can be conceptually divided into two independent but strongly interconnected parts. This is due to the fact that the sales forecast values of the first part are the input data for the Production Redesign. It can be easily noticed that stochasticity is widely present in both phases and that for the forecast phase a survey of the literature does not produce sufficient elements to identify a correct methodology for the case study. For these reasons the authors decide to define a methodology able to reduce the risk of finding results that do not fit the real system behaviour. So, since the problem studied is stochastic, the adopted models have to be able to face the stochastic regime with known statistical efficiency and reliability. Starting from these considerations the authors use the Monte Carlo simulation which allows to make the forecast information dynamic and to add to the mean sales their tolerance intervals whose amplitude increases as the time increases. The subsequent use of the DES allows the authors to redesign the production system considering a variable configuration as the sales increase. Finally, using the RSM technique, the authors analyse how the objective function, represented by the Gross margin, evolves as the described conditions change, highlighting the advantages in terms of economy of scale. The proposed approach allows providing decision managers an effective view on the possible future developments keeping, however, the awareness of a high stochasticity level. Finally the authors wish to remark that the identified methodology is easily replicable in the study of production systems similar to the one presented in the paper. 


\section{REFERENCES}

[1] Cassettari, L.; Mosca, R.; Revetria, R. (2010). Experimental error measurement in Monte Carlo simulation, Abu-Taieh, E. M. O.; El-Sheikh, A. A. (Eds.), Handbook of research on discrete event simulation environments: Technologies and applications, IGI Global, Hershey, 92-142, doi:10.4018/978-1-60566-774-4.ch006

[2] Cassettari, L.; Giribone, P. G.; Mosca, M.; Mosca, R. (2010). The stochastic analysis of investments in industrial plants by simulation models with control of experimental error: theory and application to a real business case, Applied Mathematical Sciences, Vol. 4, No. 76, 38233840

[3] Mosca, R.; Bruzzone, A. G.; Cassettari, L.; Mosca, M. (2009). Risk analysis for industrial plants projects: an innovative approach based on simulation techniques with experimental error control, Proceedings of the $21^{\text {st }}$ European Modelling and Simulation Symposium (EMSS'09), 143-147

[4] Cassettari, L.; Mosca, R.; Revetria, R.; Rolando, F. (2012). Sizing of a 3,000,000t bulk cargo port through discrete and stochastic simulation integrated with response surface methodology techniques, International Journal of Systems Applications, Engineering \& Development, Vol. 6, No. 1, 87-97

[5] Cassettari, L.; Mosca, R.; Revetria, R.; Rolando, F. (2013). Effectiveness and limits of response surface methodology in application to discrete and stochastic simulation of manufacturing plants, Applied Mathematical Sciences, Vol. 7, No. 83, 4137-4172, doi:10.12988/ams.2013.212634

[6] Cassettari, L.; Mosca, M.; Mosca, R.; Rolando, F. (2013). The yearly production of a manufacturing plant studied by DES combined with RSM high level designs and neural networks, International Journal of Mathematics and Computers in Simulation, Vol. 7, No. 4, 345-354

[7] Fildes, R.; Hastings, R. (1994). The organization and improvement of market forecasting, Journal of the Operational Research Society, Vol. 45, No. 1, 1-16, doi:10.1038/sj/jors/0450101

[8] Dalrymple, D. J. (1987). Sales forecasting practices: results from a United States survey, International Journal of Forecasting, Vol. 3, No. 3-4, 379-391, doi:10.1016/01692070(87)90031-8

[9] Drury, D. H. (1990). Issues in forecasting management, Management International Review, Vol. 30, No. 4, 317-329

[10] Chang, P.-C.; Wang, C.-P.; Yuan, B. J. C.; Chuang, K.-T. (2002). Forecast of development trends in Taiwan's machinery industry, Technological Forecasting and Social Change, Vol. 69, No. 8, 781-802, doi:10.1016/S0040-1625(00)00117-7

[11] Scherer, F. M. (1982).The office of technology assessment and forecast industry concordance as a means of identifying industry technology origins, World Patent Information, Vol. 4, No. 1, 12 17, doi:10.1016/0172-2190(82)90086-2

[12] Fernandez, V. (2007). Wavelet- and SVM-based forecasts: an analysis of the U.S. metal and materials manufacturing industry, Resources Policy, Vol. 32, No. 1-2, 80-89, doi:10.1016/j.resourpol.2007.06.002

[13] Lin, C.-T.; Yang, S.-Y. (2003). Forecast of the output value of Taiwan's opto-electronics industry using the Grey forecasting model, Technological Forecasting and Social Change, Vol. 70, No. 2, 177-186, doi:10.1016/S0040-1625(01)00191-3

[14] Bates, J. M.; Granger, C. W. J. (1969). The combination of forecasts, OR, Vol. 20, No. 4, 451468, doi: $10.2307 / 3008764$

[15] Guo, G.; Roettger, M. E.; Cai, T. (2008). The integration of genetic propensities into socialcontrol models of delinquency and violence among male youths, American Sociological Review, Vol. 73, No. 4, 543-568, doi:10.1177/000312240807300402

[16] Martino, J. P. (1993). Technological Forecasting for Decision Making, $3^{\text {rd }}$ ed., McGraw-Hill, New York

[17] Shakouri, G. H.; Nadimi, R.; Ghaderi, F. (2009). A hybrid TSK-FR model to study short-term variations of the electricity demand versus the temperature changes, Expert Systems with Applications, Vol. 36, No. 2, 1765-1772, doi:10.1016/j.eswa.2007.12.058

[18] Tseng, F.-M.; Hu, Y.-C. (2009). Quadratic-interval Bass model for new product sales diffusion, Expert Systems with Applications, Vol. 36, No. 4, 8496-8502, doi:10.1016/j.eswa.2008.10.078 
[19] Stock, J. H.; Watson, M. W. (1998). A comparison of linear and nonlinear univariate models for forecasting macroeconomic time series, NBER working paper series, No. 6607, National Bureau of Economic Research, Cambridge, doi:10.3386/w6607

[20] Chen, K.-Y. (2011).Combining linear and nonlinear model in forecasting tourism demand, Expert Systems with Applications, Vol. 38, No.8, 10368-10376, doi:10.1016/j.eswa.2011.02.049

[21] Bissoondeeal, R. K.; Binner, J. M.; Bhuruth, M.; Gazely, A. (2008). Forecasting exchange rates with linear and nonlinear models, Global Business and Economics Review, Vol. 10, No.4, 414429, doi:10.1504/GBER.2008.020593

[22] Orbach,Y.; Fruchter, G. E. (2011). Forecasting sales and product evolution: The case of the hybrid/electric car, Technological Forecasting and Social Change, Vol. 78, No. 7, 1210-1226, doi:10.1016/j.techfore.2011.03.018

[23] Bayus, B. L. (1987). Forecasting sales of new contingent products: an application to the compact disk market, Journal of Product Innovation Management, Vol. 4, No. 4, 243-255, doi: $10.1111 / 1540-5885.440243$

[24] Winklhofer, H.; Diamantopoulos, A. (2003). A model of export sales forecasting behavior and performance: development and testing, International Journal of Forecasting, Vol. 19, No. 2, 271 285, doi:10.1016/S0169-2070(01)00146-7

[25] Lin, C.-C.; Lin, C.-L.; Shyu, J. Z. (2014). Hybrid multi-model forecasting system: a case study on display market, Knowledge-Based Systems, Vol. 71, 279-289, doi:10.1016/j.knosys.2014.08.004

[26] Kelliher, C. F.; Mahoney, L. S. (2000). Using Monte Carlo simulation to improve long-term investment decisions, The Appraisal Journal, Vol. 68, No. 1, 44-56

[27] Cassettari, L.; Mosca, R.; Revetria, R. (2012). Monte Carlo simulation models evolving in replicated runs: a methodology to choose the optimal experimental sample size, Mathematical Problems in Engineering, Vol. 2012, paper ID 463873, 17 pages, doi:10.1155/2012/463873

[28] Abu-Taieh, E. M. O.; El-Sheikh, A. A. (Eds.), Handbook of research on discrete event simulation environments: Technologies and applications, IGI Global, Hershey, doi:10.4018/978-1-60566$\underline{774-4}$

[29] Mosca, R.; Giribone, P. (1982). Optimal length in O.R. simulation experiments of large scale production system, Proceedings of the IASTED International Symposium on Modelling, Identification and Control, 78-82

[30] Box, G. E. P.; Draper, N. R. (Eds.) (1987). Empirical Model-Building and Response Surfaces, John Wiley \& Sons, New York

[31] Myers, R. H.; Montgomery, D.C. (Eds.) (1995). Response Surface Methodology, John Wiley \& Sons, New York

[32] Montgomery, D.C. (Ed.) (2005). Design and Analysis of Experiments, John Wiley \& Sons, New York

[33] Draper, N. R.; Smith, H. (1998). Applied Regression Analysis, $3^{\text {rd }}$ ed., John Wiley \& Sons, New York 